RESEARCH PAPER

\title{
The wealth effects of smoking
}

\section{J L Zagorsky}

Tobacco Control 2004;13:370-374. doi: 10.1136/tc.2004.008243

\begin{abstract}
Objective: To investigate the impact of smoking on the wealth of US young baby boomers.
Methodology: The research analyses self reported responses of both smoking habits and wealth holdings from a nationally representative sample of US individuals born between 1957 to 1964 (n = 8908). Data are from four waves $(1984,1992,1994,1998)$ of the National Longitudinal Survey of Youth 1979 cohort, a random survey of individuals conducted by the US Department of Labor using a stratified multistage area sample design.

Results: Regression results show lower net worth is associated with smoking, after holding constant a variety of demographic factors. Respondents who were ever heavy smokers are associated with a reduction in net worth of over $\$ 8300$ while light smokers are $\$ 2000$ poorer compared to non-smokers. Beyond this reduction, each adult year of smoking is associated with a decrease in net worth of $\$ 410$ or almost $4 \%$.

Conclusions: While a causal relation cannot be proven, smokers appear to pay for tobacco expenditures out of income that is saved by non-smokers. Hence, reductions in smoking will boost wealth, especially among the poor.
\end{abstract}

Correspondence to: Jay Zagorsky, Ohio State University, 921 Chatham Lane, Suite 100 Columbus, $\mathrm{OH} 43221$ USA; zagorsky.1@osu.edu

Received 16 March 2004 Accepted 11 August 2004
W hile smoking's harmful health effects are well known, the individual wealth effects of smoking have received much less investigation. Analysis of US expenditure data show that the average US smoker spends over $\$ 700$ a year on tobacco products, which for the average US family comprises a large proportion of discretionary spending. ${ }^{1}$ In many other countries higher cigarette taxes and cigarette prices, ${ }^{2}$ and lower incomes, ${ }^{3}$ result in smoking expenditures being an even larger proportion of discretionary spending than in the USA. Since discretionary spending could also be saved, this research investigates smoking's impact on the wealth of US young baby boomers and finds smoking is associated with dramatically reduced wealth.

Theoretically smoking can have only three possible effects on wealth; reduce, increase, or no effect. A possible way smoking could increase wealth is if individuals use tobacco to dull their taste buds, causing them to spend less on food consumption. ${ }^{45}$ If the savings from reduced food consumption are greater than the amount smokers spend on tobacco then wealth is increased. An example of smoking having no impact is if smokers reduce their spending on other items, like entertainment or alcohol, to directly finance their smoking habit. An example of smoking decreasing wealth is if smokers and non-smokers have identical non-tobacco spending patterns, then all money spent on tobacco directly reduces smokers' savings compared to non-smokers. Given all three cases are possible, the only method of resolving the impact of smoking on wealth is to track actual outcomes.

Previous research has looked indirectly at smoking's impact on wealth. Levine et $a l^{6}$ examined the wages of smokers and non-smokers. They found that even after taking into account a variety of demographic and other characteristics, smokers earned between $4-8 \%$ less than non-smokers. $\mathrm{Ruhm}^{7}$ finds that smoking is related to economic conditions and shows that smoking increases during upturns in the economy, when individuals are richer, and decreases during downturns, when individuals are poorer.

Decker and Schwartz ${ }^{8}$ examine the effect of changes in the price of alcohol and cigarettes on individual's consumption. They find higher alcohol prices decreased usage of both alcohol and cigarettes. Higher cigarette prices, however, decreased smoking but actually increased drinking. Thus most smokers and drinkers are not blindly addicted but modify their behaviour partially based on financial considerations. Siahpush and colleagues ${ }^{9}$ examine the relation between smoking and financial stress and find smoking is a significant predictor of financial stress. Finally, Browning ${ }^{10}$ shows that spending on smoking among people in Great Britain did not fall dramatically during the key ages when children were born. His research suggests that smokers do not make significant changes in their spending habits when major new expenses are incurred.

\section{METHODS}

This research uses the National Longitudinal Survey of Youth (NLSY79) to track the smoking and wealth of US young baby boomers. Young baby boomers are individuals born between 1957 and 1964, at the tail end of the population explosion that started in the late 1940s. Young baby boomers are of particular importance in understanding US smoking patterns because they were the first generation to grow up clearly being warned of tobacco's dangers before ever trying the product.

The NLSY79 is a stratified multistage area sample covering the entire USA that was started in 1979 by the US Department of Labor. This ongoing sample has tracked the lives of approximately 10000 people 20 times from 1979 to 2002. The survey over-sampled poor individuals, blacks, and Hispanics. This research uses the survey weights to correct for the over-sampling and complex sample design so that all reported results are representative of US national totals. Additional survey details are found in Zagorsky. ${ }^{11}$ This research starts in 1984 and ends in 1998, which are the first and last surveys that include smoking information.

\section{Smoking status}

Survey respondents were asked to self report smoking status four different times. During the 1984 survey respondents

Abbreviations: AFQT, Armed Forces Qualification Test; NLSY79, National Longitudinal Survey of Youth 1979 
were asked if they had ever tried a cigarette. For those who had smoked, the age they first used a cigarette, the most recent time they had used cigarettes, and the number of cigarettes smoked in the past 30 days were recorded. Then in 1992, 1994, and again in 1998 respondents were asked if they had smoked at least 100 cigarettes so far in their life. If they stated yes, they were asked if they smoked daily. Daily smokers were further asked when they started smoking daily, their current smoking status, and how many cigarettes they smoked each day. If respondents were no long daily smokers they were asked how long it was since they last smoked daily.

Using this information five variables were created. The first, "ever smoke", captures if a respondent ever used more than 100 cigarettes. The second, "heavy smoker", captures if a respondent ever reported smoking a pack (20 cigarettes) or more per day on average. The third, "light smoker", is defined as individuals who reported ever smoking but never smoked more than a pack a day. The last two variables, "years smoked" and "years adult smoker", track both the total number of years and the total since they were 18 years old that the respondent smoked.

All respondents analysed participated in at least three out of the four NLSY79 surveys that asked smoking questions to ensure a relatively complete smoking history. The criteria resulted in dropping $10.6 \%$ of the NLSY79 sample, leaving 8908 respondents for analysis. Changing the selection criteria did not qualitatively modify results.

NLSY79 smoking questions have exceptionally high response rates. For example, in the 1998 survey just 57 out of the 8390 respondents did not answer the question: Have you ever smoked at least 100 cigarettes in your life? Moreover, many non-responders provide data in one survey, but not another. Each respondent analysed provided at least one valid observation for the ever smoked variable and $99.8 \%$ provided valid answers more than once.

\section{RESULTS}

Table 1 provides basic information about smoking among young baby boomers. The ever smoke row shows that more than half $(57.6 \%)$ of all boomers reported smoking at least 100 cigarettes during their life. Males $(58.1 \%)$ reported only slightly higher smoking rates than females $(57.0 \%)$. While these rates are not statistically distinguishable $(\mathrm{p}<0.26)$ using the Cochran-Mantel-Haenszel $(\mathrm{CMH})$ test, the other rates in the table are $(\mathrm{p}<0.01)$. The heavy smoker row shows $22.6 \%$ of young baby boomers smoked at least a pack a day sometime in their life, with men $(25.4 \%)$ far more likely than women $(19.8 \%)$ to be heavy smokers. The light smoker row shows slightly more than one third (35\%) of young baby boomers smoked, but never at the pack a day level. Light smokers include both occasional smokers and individuals who smoke daily. Because occasional smokers were such a small group (5.6\% of all smokers) they were not broken out separately in this research.

Table 1 Extent of smoking by US young baby boomers

\begin{tabular}{llll}
\hline & Overall & Men & Women \\
\hline Ever smoke & $57.6 \%(0.8 \%)$ & $58.1 \%(1.0 \%)$ & $57.0 \%(1.0 \%)$ \\
Heary smoker & $22.6 \%(0.7 \%)$ & $25.4 \%(1.0 \%)$ & $19.8 \%(0.8 \%)$ \\
Light smoker & $35.0 \%(0.8 \%)$ & $32.7 \%(1.0 \%)$ & $37.2 \%(1.0 \%)$ \\
Years smoked & $10.6(0.1)$ & $10.6(0.2)$ & $10.6(0.2)$ \\
Years adult smoker & $7.4(0.1)$ & $7.5(0.2)$ & $7.4(0.1)$ \\
\hline
\end{tabular}

"Years smoked" and "Years adult smoker" calculations exclude nonsmokers. Adult is defined as greater than 18 years old. Corrected standard errors (SEs) are in parentheses.
Table 2 Demographics of young baby boomers by smoking status in 1998

\begin{tabular}{lllll}
\hline & Overall & $\begin{array}{l}\text { Never } \\
\text { smoked }\end{array}$ & $\begin{array}{l}\text { Light } \\
\text { smoker }\end{array}$ & $\begin{array}{l}\text { Heavy } \\
\text { smoker }\end{array}$ \\
\hline White $^{* * *}$ & $78.6 \%$ & $78.0 \%$ & $74.3 \%$ & $86.4 \%$ \\
Black** $_{\text {Hispanic** }}^{* *}$ & $14.7 \%$ & $14.9 \%$ & $17.5 \%$ & $10.1 \%$ \\
Age & $6.6 \%$ & $7.1 \%$ & $8.2 \%$ & $3.4 \%$ \\
& 36.7 & 36.6 & 36.8 & 36.7 \\
\% Female & & & & \\
Income & $51 \%$ & $51 \%$ & $54 \%$ & $44 \%$ \\
AFQT $^{* * *}$ & $\$ 59243$ & $\$ 68788$ & $\$ 58156$ & $\$ 42962$ \\
High school degree $^{* * *}$ & 47.9 & 54.3 & 46.0 & 38.8 \\
Started college & $90 \%$ & $94 \%$ & $91 \%$ & $79 \%$ \\
& $50 \%$ & $61 \%$ & $50 \%$ & $28 \%$ \\
Married & & & & \\
Number children & $69 \%$ & $74 \%$ & $68 \%$ & $63 \%$ \\
Number siblings & 1.7 & 1.6 & 1.7 & 1.7 \\
Number of respondents & 3.3 & 3.1 & 3.5 & 3.5 \\
\hline
\end{tabular}

All variables are weighted using the survey weights, except for number of respondents. Income is adjusted to be in $\mathbf{2 0 0 0}$ dollars.

***The three values in the "Never smoked", "Light smoker", and "Heavy smoker" columns are all statistically distinct from each other at $\mathrm{p}<0.01$ or higher level; ${ }^{* *}$ and * are distinct at 0.05 and 0.10 levels respectively.

The last two rows track the average time a person smoked. These rows exclude all individuals who smoked less than 100 cigarettes in their lifetime and cover from the time a respondent started until they either quit or were last asked smoking questions. On average the typical smoker has been smoking for over a decade (10.6 years) of their entire life and for almost seven and a half years of their adult lives. Given the typical young baby boomer was less than 37 years old when the last smoking questions were asked, the average boomer who ever smoked has done so for almost $40 \%$ of their adult life. While many boomers smoke for long periods of time, many also quit. The 1998 survey asked respondents if during their life they ever smoked daily. Among those who classified themselves as a daily smoker, 57\% still smoked daily, 33\% had quit smoking, and $10 \%$ smoked only occasionally.

\section{Demographics}

Table 2 tracks the demographics of young baby boomers who did and did not smoke in 1998. The top section shows that whites are over-represented among heavy smokers, blacks and Hispanics are over represented among the light smokers, and the typical individual analysed was almost 37 years old. The table's middle shows while the overall sample is roughly evenly split between males and females, fewer heavy smokers are women and smoking less is correlated with higher income.

AFQT (Armed Forces qualification test) scores are used by many in the research community, like Hernstein and Murray, ${ }^{12}$ as a proxy for IQ. By adding roughly 50 points to the AFQT score it approximates IQ. Like income, AFQT scores are inversely related to smoking status with individuals who never smoked (54.3) having the highest and heavy smokers (38.8) the lowest scores. Education is also inversely related to smoking status with fewer heavy smokers finishing high school or starting college.

The lower part of table 2 shows that marital status is also inversely related to smoking status, but smokers have slightly more children and come from slightly larger families than non-smokers. The final row shows that this research is based on information from almost 9000 individuals. In general the table shows that heavy smokers tend to be more often white, more often male, less often married, lower educated, and having lower intelligence than the overall population. 
Table 3 Median net worth of young baby boomers by smoking status, in 2000 dollars

\begin{tabular}{lllll}
\hline \multicolumn{2}{c}{ Overall } & Never smoked & Light smoker & Heavy smoker \\
\hline 1985 & $\$ 4807(\$ 280)$ & $\$ 6289(\$ 422)$ & $\$ 4889(\$ 362)$ & $\$ 3097(\$ 234)$ \\
1992 & $\$ 20679(\$ 1213)$ & $\$ 30658(\$ 2195)$ & $\$ 18894(\$ 1669)$ & $\$ 9395(\$ 1026)$ \\
1994 & $\$ 30135(\$ 1658)$ & $\$ 45168(\$ 2410)$ & $\$ 27030(\$ 1962)$ & $\$ 12472(\$ 1054)$ \\
1998 & $\$ 50751(\$ 2886)$ & $\$ 73298(\$ 3866)$ & $\$ 49214(\$ 3748)$ & $\$ 23058(\$ 2061)$ \\
\hline
\end{tabular}

Corrected SEs are in parentheses. The first wealth module was fielded in 1985, one year after the first set of smoking questions were asked. All other wealth information comes from the same survey as the smoking questions.

\section{Wealth}

NLSY79 wealth questions began in 1985 when the youngest respondents were almost 21 years old. Since then survey respondents periodically report details about their assets and liabilities. Each wealth module follows the same simple pattern. Respondents are first asked if they or their spouse currently owe a debt or have an asset. If they answer yes, the interviewer asks them to state the current market value.

Summing all the asset answers for each respondent in each wealth module and subtracting from that total all debt answers creates total net worth from each survey. While the complete details of constructing the computed net worth series are described in Zagorsky, ${ }^{13}$ the key equation sums home values, cash saving, stocks, bonds, mutual funds, trusts, business, farms, other real estate, vehicle values, major possessions, and retirement accounts. Subtracted from that

\begin{tabular}{|c|c|c|}
\hline & Column 1 & Column 2 \\
\hline \multicolumn{3}{|l|}{ Smoking status $\dagger$} \\
\hline Heavy smoker & $\begin{array}{l}-\$ 8359 * * * \\
(\$ 2459)\end{array}$ & $\begin{array}{l}-91.2 \% \text { (*** } \\
(0.17 \%)\end{array}$ \\
\hline Light smoker & $\begin{array}{l}-\$ 2083 \\
(\$ 1775)\end{array}$ & $\begin{array}{l}-27.8 \%^{* *} \\
(0.12 \%)\end{array}$ \\
\hline Years adult smoker & $\begin{array}{l}-\$ 410^{* * *} \\
(\$ 158)\end{array}$ & $\begin{array}{l}-3.7 \% \text { *** } \\
(0.01 \%)\end{array}$ \\
\hline Like risk & $\begin{array}{l}\$ 1378 \\
(\$ 1321)\end{array}$ & $\begin{array}{l}-32.9 \% * * * \\
(0.09 \%)\end{array}$ \\
\hline \multicolumn{3}{|l|}{ Race } \\
\hline Black & $\begin{array}{l}-\$ 22523^{\star * \star} \\
(\$ 1915)\end{array}$ & $\begin{array}{l}-164.6 \% \text { *** } \\
(0.13 \%)\end{array}$ \\
\hline Hispanic & $\begin{array}{l}-\$ 16335^{\star \star *} \\
(\$ 2209)\end{array}$ & $\begin{array}{l}-90.8 \% \text { *** } \\
(0.16 \%)\end{array}$ \\
\hline Age & $\begin{array}{l}\$ 2539^{* * *} \\
(\$ 358)\end{array}$ & $\begin{array}{l}17.4 \%^{* \star *} \\
(0.02 \%)\end{array}$ \\
\hline Female & $\begin{array}{l}-\$ 473 \\
(\$ 1513)\end{array}$ & $\begin{array}{l}-59.5 \%{ }^{* * *} \\
(0.08 \%)\end{array}$ \\
\hline$I Q$ & $\begin{array}{l}\$ 85^{* *} \\
(\$ 38)\end{array}$ & $\begin{array}{l}0.7 \% \%^{* * \star} \\
(0.001 \%)\end{array}$ \\
\hline Number of siblings & $\begin{array}{l}-\$ 817^{* * *} \\
(\$ 242)\end{array}$ & $\begin{array}{l}-5.1 \% \%^{* * *} \\
(0.02 \%)\end{array}$ \\
\hline Survey year & $\begin{array}{l}\$ 2764^{* * *} \\
(\$ 205)\end{array}$ & $\begin{array}{l}10.1 \%^{* \star *} \\
(0.01 \%)\end{array}$ \\
\hline High grade completed & $\begin{array}{l}\$ 1580^{* * *} \\
(\$ 480)\end{array}$ & $\begin{array}{l}7.8 \% * * * \\
(0.02 \%)\end{array}$ \\
\hline Married & $\begin{array}{l}\$ 3382^{* *} \\
(\$ 1514)\end{array}$ & $\begin{array}{l}172.9 \% \text { *** } \\
(0.10 \%)\end{array}$ \\
\hline Number of children & $\begin{array}{l}\$ 738 \\
(\$ 571)\end{array}$ & $\begin{array}{l}-23.4 \%^{* * *} \\
(0.04 \%)\end{array}$ \\
\hline Income & $\begin{array}{l}\$ 1.25^{* \star \star} \\
(\$ 0.06)\end{array}$ & $\begin{array}{l}0.0035 \% \text { *** } \\
(0.000001 \%)\end{array}$ \\
\hline Intercept & $\begin{array}{l}-\$ 119230^{* * *} \\
(\$ 14279)\end{array}$ & $\begin{array}{l}-163.9 \%{ }^{* *} \\
(0.75 \%)\end{array}$ \\
\hline$R^{2}$ & 0.30 & 0.18 \\
\hline Number of observations & 31588 & 31804 \\
\hline \multicolumn{3}{|c|}{$\begin{array}{l}\text { For explanation of columns } 1 \text { and } 2 \text { see text. } \\
{ }_{* * *} \text { Value significant at the } 0.01 \text { or higher level; }{ }^{* *} \text { significant at } 0.05 \text {; } \\
{ }^{*} \text { significant at } 0.10 \text {. } \\
\text { †Reference category is non-smoker. } \\
\ddagger \text { Reference category is white. } \\
\text { Survey year is equal to the actual year minus } 1985 \text {. }\end{array}$} \\
\hline
\end{tabular}

total are the total debts outstanding on homes, businesses, farms, real estate, vehicles, credit cards and other items. After the total was computed all values were adjusted to account for inflation so amounts are in 2000 dollars.

\section{Smoking-wealth relation}

What general relation exists between smoking and wealth? Table 3 shows the median net worth held overall by young baby boomers and then broken down by smoker status. In general the table shows two key facts. First, the median boomer has relatively little net worth no matter which year is examined, with the typical boomer holding less than \$75000 in every year and category analysed. Second, those who never smoked have much higher net worth in every survey than those who smoked. Among those who smoke, light smokers fare financially much better than heavy smokers. On average the net worth of those who never smoked is roughly $50 \%$ higher than individuals who are light smokers and more than twice the level of heavy smokers.

These findings are statistically robust. Values reported in the never smoked, light smoker, and heavy smoker columns are highly distinct from each other at the $\mathrm{p}<0.01$ level in the 1992, 1994, and 1998 surveys and distinct at $p<0.10$ in 1985. Moreover, while median values are reported to avoid the dramatic fluctuations caused by the presence or absence of very rich individuals, examining the mean value table (not shown) reveals very similar results except that all values are roughly a factor of two higher.

\section{Analysis}

Table 3 shows young baby boomers that smoke have less wealth than non-smokers. However, table 2 shows that smokers are found in lower socioeconomic strata than nonsmokers. To separate these effects regressions were run to estimate the impact of smoking on wealth while controlling for most of the socioeconomic status variables found in table 2 .

To adjust for the complex sample design all regressions were done in a linear generalised estimating equation, or GEE framework, discussed in Liang and Zeger, ${ }^{14}$ using the Sudaan 8.0 statistical package. Data on each respondent's original replicate and strata were obtained from the NLSY79 Geocode CD-ROM and used to compute corrected standard errors.

Table 4 combines the data from all four NLSY79 smoking surveys and shows the effect on net worth in column 1 and the natural $\log$ of net worth in column 2 of smoking and other key demographic variables, with corrected standard errors in parentheses. To ensure that the small number of extremely wealthy individuals do not exert an undue influence on the results, the top $1 \%$ of wealth values in each year were eliminated when estimating column 1 . No values were eliminated when estimating column 2 since the natural $\log$ transformation reduces the effect of outliers. Since the natural $\log$ of negative numbers is not defined, the Kennickell-Woodburn ${ }^{15}$ wealth transformation, which is the $\operatorname{sign}(x){ }^{*} \log _{e}(\operatorname{abs}(x))$, was used for all values. 
Holding other socioeconomic factors constant respondents who ever reported being a heavy smoker are associated with a reduction in net worth of almost $\$ 8400$ compared to nonsmokers. Respondents who reported ever being a light smoker are associated with a net worth almost \$2100 less than non-smokers. Beyond these reductions each year a respondent smoked during their adult life resulted in an additional drop of $\$ 410$, or $3.7 \%$. While the heavy smoker and years adult smoker coefficients are highly significant $(\mathrm{p}<0.01)$, the light smoker coefficient in column 1 is not significant $(p<0.23)$ even though its counterpart in column 2 is $(p<0.02)$.

Smokers, who have been warned extensively about risks of smoking, are often thought to have a different risk tolerance than non-smokers. By smoking they show a willingness to bear future higher risks of health problems than nonsmokers. Wealth and risk are also related since not only do riskier investments on average pay higher returns than safe investments, but the premium to hold risky investments in the USA has consistently been in excess of what theoretically should exist. ${ }^{16}$

Using a series of risk tolerance questions fielded in 1993 each respondent was classified as generally liking or not liking risk. Three facts suggest that the smoking net worth results are not influenced by smokers' general risk tolerance: first, the inclusion of risk tolerance did not improve either model's fit, as measured by $R^{2}$; second, the risk coefficient in column 1 is not significant from zero; third, the coefficient's sign changes from positive to negative between the two columns.

The rest of the coefficients show that black and Hispanic respondents are associated with lower wealth than white respondents, who are the omitted group. Being older, more educated, married and having a higher income are associated with young boomers having increased wealth, while having more brothers and sisters is associated with decreased wealth. Interestingly, the effects of each one point IQ increase, being female, and each additional child are either quantitatively unimportant or statistically indistinguishable from zero, suggesting they are not important determinants.

Re-running the regressions separately for each individual year (not shown), instead of pooling the data, shows the smoking coefficients increase as boomers age. For example, the coefficient for "years adult smoker" in the 1985 survey, when most boomers were in their early 20 s, is just $-\$ 92$. However, by 1998, when boomers were in their late 30s, each year of adult smoking reduces wealth by $\$ 860$. Growing coefficients suggest the detrimental financial impact of smoking increases as the cohort ages.

\section{DISCUSSION}

This research investigated the effect of smoking on an individual's financial situation. Using the NLSY79 cohort, which tracks the life experiences of the US young baby boomer cohort, this research finds the typical non-smokers' net worth is roughly $50 \%$ higher than light smokers and more than twice the level of heavy smokers.

Demographic information shows that the typical smoker has many factors normally associated with lower wealth levels, such as less education, income, and chance of being married. Regression results, which hold these sociodemographic factors constant, show respondents who ever were heavy smokers had a net worth that was lower by $\$ 8300$ and light smokers had a net worth lower by over $\$ 2000$ than nonsmokers. In addition to this fixed penalty, each adult year of smoking caused net worth to fall by an additional $\$ 410$ or almost $4 \%$. Since the average smoker did so for almost 7.5 years, the total penalty for the typical heavy smoker penalty is

\section{What this paper adds}

While the harmful health effects of smoking are well known, the economic effects of smoking have received much less investigation. This is the first paper to directly investigate the impact of smoking on wealth.

almost \$11 400 and the total penalty for the typical light smoker is $\$ 5100$.

Smoking expenditure data ${ }^{1}$ suggest that these wealth reductions are roughly equal to the amounts spent by smokers. This suggests, but cannot prove, smokers maintain spending habits on other items and pay for expenditures on tobacco out of income that would normally be saved.

Some caveats apply to these results. First, the findings are for only one cohort of US individuals. Individuals in other countries and in other age ranges may have a very different smoking-wealth relation. Second, while the results infer a causal relation, this causality can not be proven, given it is illegal to run a controlled experiment that randomly assigns individuals to a particular smoking status. Last, while the regressions hold constant many important factors, there is the possibility wealth and smoking are both related to a missing common set of factors, such as stress and anxiety, which is actually driving the relation.

Even with these caveats the findings have interesting implications. First, lower wealth holdings are potentially the outcome of rational decisions. Research shows the most important reason given for saving in the USA is to have funds for retirement. ${ }^{17}$ Because smokers have a lower life expectancy than non-smokers, they spend less time being retired. If smokers expect shorter retirements, then their financial needs are lower than non-smokers and they have a smaller incentive to save and build wealth.

While lower wealth may be a rational individual choice, the decision to save less is not an optimal societal choice. Lower wealth means many smokers are not saving for, nor will they have in the future, the financial resources to cope with expensive medical conditions. Given smokers on average have higher medical bills, any inability to cover private medical costs from their savings or income must be covered by increased public health expenditures.

Last, lower wealth means smokers with children have fewer financial resources to spend on their progeny. As Hao ${ }^{18}$ points out, the "economic well-being of families with children is an important factor affecting children's outcomes". Hence, current smoking has negative inter-generational effects that go beyond the health effects identified in the literature.

Overall, the results show smoking appears to adversely affect finances. While successful smoking control programmes improve health, these programmes potentially have a secondary impact-improving wealth.

Competing interest statement: I have no competing interest in relation to this paper.

\section{REFERENCES}

1 Bureau of Labor Statistics. Consumer expenditure survey, 1996-97, Report 935 Washington, DC., 1999.

2 Chaloupka F, Hu T, Warner K, et al. The taxation of tobacco products. In: Jha P, Chaloupka F, eds. Tobacco control in developing countries. Oxford: Oxford University Press, 2000:237-72.

3 World Bank. World development indicators 2004. Washington DC: World Bank, 2004.

4 Klesges RC, Elliott VE, Robinson LA. Chronic dieting and the belief that smoking controls body weight in a biracial, population-based adolescent sample. Tobacco Control 1997;6:89-94. 
5 Christina W, Rigotti N, Davis R, et al. Relationship between smoking and weight control efforts among adults in the United States. Arch Intern Med 2001;161:546-50.

6 Levine P, Gustafson T, Velenchik A. More bad news for smokers? The effects of cigarette smoking on wages. Industrial and Labor Relations Review 1997; 50:493-509.

7 Ruhm C. Are recessions good for your health? Quarterly Journal of Economics 2000; 115:617-50.

8 Decker SL, Schwartz AE. Cigarettes and alcohol: substitutes or complements? NBER Working Paper 7535, Cambridge, Massachusetts, 2000

9 Siahpush M, Borland R, Scollo M. Smoking and financial stress. Tobacco Control 2003; 12:60-6.

10 Browning M. Eating, drinking, smoking, and testing the lifecycle hypothesis. Quarterly Journal of Economics 1987; 102:329-46.

11 Zagorsky JL. NLSY79 users' guide, Center For Human Resource Research, The Ohio State University, Columbus, Ohio, 1997
12 Hernstein, R, Murray C. The bell curve: intelligence and class structure in American life. New York: Free Press, 1994.

13 Zagorsky JL. Young baby boomers wealth. Review of Income and Wealth 1999;45:135-56.

14 Liang, KY, Zeger S. Longitudinal data analysis using generalized linear models. Biometrika 1986;73:13-22.

15 Kennickell AB, Woodburn, RL. Consistent weight design for the 1989, 1992 and 1995 SCF's, and the distribution of wealth. Review of Income and Wealth 1999;45:193-216.

16 Kocherlakota N. The equity premium: it's still a puzzle. Journal of Economic Literature 1996;34:42-71.

17 Aizcorbe A, Kennickell A, Moore K. Recent changes in U.S. family finances: evidence from the 1998 and 2001 survey of consumer finances, Federal Reserve Bulletin 2003:1-32.

18 Hao L. Family structure, private transfers, and the economic well-being of families with children. Social Forces 1996;75:269-92

\section{Clinical Evidence-Call for contributors}

Clinical Evidence is a regularly updated evidence-based journal available worldwide both as a paper version and on the internet. Clinical Evidence needs to recruit a number of new contributors. Contributors are healthcare professionals or epidemiologists with experience in evidence-based medicine and the ability to write in a concise and structured way.

\section{Areas for which we are currently seeking authors:}

- Child health: nocturnal enuresis

- Eye disorders: bacterial conjunctivitis

- Male health: prostate cancer (metastatic)

- Women's health: pre-menstrual syndrome; pyelonephritis in non-pregnant women

However, we are always looking for others, so do not let this list discourage you.

\section{Being a contributor involves:}

- Selecting from a validated, screened search (performed by in-house Information Specialists) epidemiologically sound studies for inclusion.

- Documenting your decisions about which studies to include on an inclusion and exclusion form, which we keep on file.

- Writing the text to a highly structured template (about 1500-3000 words), using evidence from the final studies chosen, within 8-10 weeks of receiving the literature search.

- Working with Clinical Evidence editors to ensure that the final text meets epidemiological and style standards.

- Updating the text every six months using any new, sound evidence that becomes available. The Clinical Evidence in-house team will conduct the searches for contributors; your task is simply to filter out high quality studies and incorporate them in the existing text.

- To expand the topic to include a new question about once every 12-18 months.

If you would like to become a contributor for Clinical Evidence or require more information about what this involves please send your contact details and a copy of your CV, clearly stating the clinical area you are interested in, to Klara Brunnhuber (kbrunnhuber@ bmigroup.com).

\section{Call for peer reviewers}

Clinical Evidence also needs to recruit a number of new peer reviewers specifically with an interest in the clinical areas stated above, and also others related to general practice. Peer reviewers are healthcare professionals or epidemiologists with experience in evidence-based medicine. As a peer reviewer you would be asked for your views on the clinical relevance, validity, and accessibility of specific topics within the journal, and their usefulness to the intended audience (international generalists and healthcare professionals, possibly with limited statistical knowledge). Topics are usually 1500-3000 words in length and we would ask you to review between 2-5 topics per year. The peer review process takes place throughout the year, and our turnaround time for each review is ideally 10-14 days.

If you are interested in becoming a peer reviewer for Clinical Evidence, please complete the peer review questionnaire at www.clinicalevidence.com or contact Klara Brunnhuber (kbrunnhuber@bmigroup.com). 